\title{
Adaptation to Taurine Deprivation in the Phosphate-Depleted Rat
}

\author{
SHERMINE DABBAGH, MARILYN EPLEY, AND WARREN DIVEN \\ Children's Hospital of Pittsburgh, University of Pittsburgh, Pittsburgh, Pennsylvania 15213 and Children's \\ Hospital of Michigan, Wayne State University, Detroit, Michigan 48201
}

\begin{abstract}
The nonessential amino acid taurine, which is inert in renal tissue, was used to study renal adaptation in the presence of phosphate $(P)$ depletion in the rat. Weanling rats were placed on the control diet $(0.7 \% \mathrm{P}$, normal taurine) for $4 \mathrm{wk}$, then fed one of the experimental diets or continued on the control diet for 1 wk. The diets used were 1) $\mathrm{P}^{+} \mathrm{T}^{-}(0.7 \% \mathrm{P}$, low taurine $\left.), 2\right) \mathrm{P}^{-} \mathrm{T}^{+}(0.1 \%$ $\mathrm{P}$, normal taurine); and 3) $\mathrm{P}^{-} \mathrm{T}^{-}(0.1 \% \mathrm{P}$, low taurine). Taurine deficiency was associated with avid tubular reabsorption of taurine, irrespective of $P$ status. This was associated with a 4- to 5-fold increase in the $V_{\max }$ of uptake ( $p$ $<0.001)$. On the other hand, $P$ depletion increased the $\mathrm{Km}$ of taurine uptake by 6.6- to 9.5-fold, suggesting a decrease in the affinity of the taurine symport $(p<0.001)$. This was independent of the taurine status of the animals. Although there was no effect of diet on the urinary excretion of $\beta$-alanine, $P$ depletion, irrespective of taurine status, resulted in a 2 -fold increase in the $\mathrm{Km}$ of $\beta$-alanine uptake. We conclude that the taurinuria of $P$ depletion is reversed in taurine deprivation. The adaptive response involves an increase in the $V_{\max }$ of uptake. However, the increase in $\mathrm{Km}$ of taurine uptake observed in $\mathrm{P}$ depletion does not reverse with taurine depletion. (Pediatr Res 30: 146-149, 1991)
\end{abstract}

\section{Abbreviations}

\section{P, phosphorus}

BBMV, brush border membrane vesicle

HEPES, $N$-2-hydroxyethylpiperazine- $N^{\prime}$-2-ethanesulfonic acid

$\mathrm{P}^{+} \mathrm{T}^{-}$, phosphate replete, taurine-depleted

$\mathrm{P}^{-} \mathrm{T}^{-}$, phosphate- and taurine-depleted

$\mathbf{P}^{-} \mathrm{T}^{+}$, phosphate-depleted, taurine replete

The renal tubular epithelium is able to conserve amino acids during periods of decreased dietary intake. Rats or mice fed diets low in sulfur-containing amino acids adapt by increasing the tubular reabsorption of these amino acids, particularly taurine $(1,2)$. The adaptive response manifests at the luminal surface by enhanced taurine uptake by BBMV prepared from rats fed these diets (3). These changes are associated with an increase in the initial rate of uptake $\left(\mathrm{V}_{\max }\right)$ rather than a decrease in the affinity of the symport $(\mathrm{Km})(3)$. The physiologic signal(s) for the observed changes relate, in part, to alterations in the renal cortical content of taurine $(4,5)$.

Received November 20, 1990, accepted April 15, 1991

Correspondence: Shermine Dabbagh, M.D., Children's Hospital of Michigan, Division of Nephrology, 3901 Beaubien Blvd., Detroit, MI 48201.

Supported in part by BRS Grant S07 RR0550724 awarded by the Biomedical Research Support Grant Program, Division of Research Resources, National Institutes of Health.
On the other hand, it has been shown that vitamin $\mathrm{D}$ - and/or phosphate-depleted rats develop taurinuria in the absence of secondary hyperparathyroidism (6). The taurinuria manifests at the renal brush border membrane by a decrease in the affinity of the taurine symport, resulting in decreased accumulation of taurine by BBMV (7). No changes could be elicited for the $V_{\max }$ of uptake. In addition, the perturbation in uptake was not associated with alterations in plasma or renal cortex taurine concentrations, suggesting that overflow is not a regulatory signal in this model.

Although the adaptive response has been shown to exist in terms of urinary excretion at the apical surface in adult rats, little is known about the response of these animals to taurine deprivation in the presence of phosphate depletion. Herein, we describe the effect of low sulfur-containing amino acid diets on the renal handling of taurine in the P-depleted rat. In addition, we examine the effect of these diets on the accumulation of $\beta$-alanine (an amino acid that is transported by the same transporter) by BBMV prepared from these animals.

\section{MATERIALS AND METHODS}

Animals. Weanling Sprague-Dawley rats (Hilltop Laboratories, Scottdale, PA) were used in this study. All experiments were performed on animals aged 55 to $58 \mathrm{~d}$ after they had been fed the specific diets for $5 \mathrm{wk}$

Diets. The animals were fed one of the diets listed in Table 1.These specific diets were prepared by Teklad Laboratories (Madison, WI). Soy protein was used because it is nearly devoid of taurine $(0.01 \% \mathrm{wt} / \mathrm{wt})$ and deficient in methionine $(0.2 \% \mathrm{wt} /$ wt) and cysteine $(0.24 \% \mathrm{wt} / \mathrm{wt})$. Supplementation with $0.6 \%$ methionine allows normal growth (8) and promotes normal taurine homeostasis (9). All diets contained $20 \%$ protein and similar amounts of salt and vitamin mix. Dietary $P$ was changed by varying the content of equimolar sodium phosphate to provide $0.7 \% \mathrm{P}$ (phosphate replete, $\mathrm{P}^{+}$) or $0.1 \% \mathrm{P}$ (phosphate depleted, $\mathrm{P}^{-}$). Because taurine is the focus of the study, the diets are described in terms of the potential for taurine bioavailability. Thus, diets replete in taurine are denoted by $\mathrm{T}^{+}$, and diets that are taurine depleted are denoted by $\mathrm{T}^{-}$.

All weanling rats (aged 20-22 d) were fed the control diet for $4 \mathrm{wk}$, then given one of the other three diets or continued on the control diet for $7 \mathrm{~d}$ [a period demonstrated to be more than adequate to induce taurine and/or $\mathrm{P}$ depletion $(1,10)$ without gross evidence of hydronephrosis or renal stone formation.] One day before they were killed, the animals were placed in metabolic cages for $10 \mathrm{~h}$ and urine was collected. To avoid the taurinuria observed in fasted rats fed low taurine diets (11), the animals had access to food and water. No attempt was made to pair-feed the animals. When the daily intake of the rats on the various diets was compared, there were no statistically significant differences among the groups (control $15 \pm 2$ versus $\mathrm{P}^{+} \mathrm{T}^{-} 14.1 \pm 1.5$ versus $\mathrm{P}^{-} \mathrm{T}^{+} 13.5 \pm 1.7$ versus $\mathrm{P}^{-} \mathrm{T}^{-} 14.8 \pm 1.6 \mathrm{~g} / \mathrm{d}$ ). This is different from the observation of Friedman et al. (12), who reported that 
Table 1. Composition of diets

\begin{tabular}{lcccc}
\hline & Control* & $\mathrm{P}^{+} \mathrm{T}^{-}$ & $\mathrm{P}^{-} \mathrm{T}^{+}$ & $\mathrm{P}^{-} \mathrm{T}^{-}$ \\
\hline Dextrose & 64 & 64 & 64 & 64 \\
Corn oil & 5 & 5 & 5 & 5 \\
Soy protein & 20 & 20 & 20 & 20 \\
Salt and vitamin mix & 9.7 & 9.7 & 9.7 & 9.7 \\
Methionine supplements & 0.6 & None & 0.6 & None \\
P & 0.7 & 0.7 & 0.1 & 0.1 \\
\hline
\end{tabular}

* Control, phosphate and taurine replete.

low taurine diets resulted in increased intake of food when compared with controls.

On the day of the experiments, the rats were lightly anesthetized with anhydrous ether, blood was obtained from the bifurcation of the aorta, and the kidneys and ureters were checked for visible hydronephrosis and stone formation. Plasma was separated by refrigerated centrifugation $\left(4^{\circ} \mathrm{C}\right)$ at $4000 \mathrm{rpm}$ and stored at $-20^{\circ} \mathrm{C}$. Plasma and urine $\mathrm{Ca}, \mathrm{P}$, and creatinine were determined, as previously described $(6,13)$. Renal cortical, plasma, and urine amino acids were separated by ion exchange chromatography as described by Moore et al. (14), and modified by Hamilton (15), using a amino acid analyzer (Perkin-Elmer Corp., Norwalk, CT).

Preparation of $B B M V$. BBMV were prepared by differential centrifugation and $\mathrm{MgCl}_{2}$ precipitation, using a modification of the method of Booth and Kenny (16), as described elsewhere (3, 17). The final pellet was suspended in THM-300 (2 mM TrisHEPES, $298 \mathrm{mM}$ mannitol, $1 \mathrm{mM} \mathrm{MgSO}$, pH 7.4) to yield a final protein concentration of $10 \pm 1 \mathrm{mg} / \mathrm{mL}$. The orientation of the vesicles thus prepared is right side out (18). Only fresh vesicles were used. BBMV protein was assayed by using Folin reagent (19). Purity of the preparation was assessed by enrichment of brush border membrane enzymes ( $\tau$-glutamyl-transferase and $5^{\prime}$-nucleotidase $(20,21)$ with respect to the original homogenate. The activities of $\tau$-glutamyl-transferase and $5^{\prime}$ nucleotidase in the final brush border fraction were 9- and 6-fold greater than in the original homogenate, respectively, signifying a pure preparation. On the other hand, ouabain-inhibitable $\mathrm{Na}$ K-ATPase (22), a marker for the basolateral membrane, was enriched by less than 0.5 -fold, indicating a noncontaminated brush border preparation. There were no differences in these enzyme activities among the various diets. Enzyme markers of other subcellular fractions (malate dehydrogenase, succinyl cytochrome $\mathbb{C}$ reductase, and $\mathrm{N}$-acetyl- $\beta$-D-glucosaminidase) in the final brush border suspension were reduced in activity relative to the starting homogenate.

Amino acid uptake studies. The uptakes of ${ }^{3} \mathrm{H}$-taurine and ${ }^{3} \mathrm{H}-$ $\beta$-alanine were assayed by the rapid Millipore filtration technique (23) at $23^{\circ} \mathrm{C}$ for 0.5 to $45 \mathrm{~min}$, after a preincubation period of 1 $\mathrm{h}$ at $23^{\circ} \mathrm{C}$. Incubation was initiated by the addition of a medium containing known amounts of unlabeled and radiolabeled taurine or $\beta$-alanine (usually $8 \mu \mathrm{Ci} / \mathrm{mL}$ reaction mixture are added) $1.05 \mathrm{mM} \mathrm{MgSO}_{4}, 50.54 \mathrm{mM}$ mannitol, $2 \mathrm{mM}$ Tris-HEPES, and $131.58 \mathrm{mM} \mathrm{NaCl}$ such as to maintain the final osmolarity at 300 mosmol and $\mathrm{Na}^{+}{ }_{\text {out }}(100 \mathrm{mM})>\mathrm{Na}^{+}{ }_{\text {in }}(0 \mathrm{mM})$. After the desired interval of time, a $50-\mu \mathrm{L}$ aliquot was placed on a prewetted 0.45 $\mu \mathrm{m}$ filter (Gelman Instrument Co., Ann Arbor, MI). The filtered sample was washed three times with $3 \mathrm{~mL}$ iced "stop solution" (containing $154 \mathrm{mM} \mathrm{NaCl}$ and $2 \mathrm{mM}$ Tris-HEPES, pH 7.4). The filters were dried overnight, dissolved in Aquasol and counted in a liquid scintillation counter (Packard TriCarb 4640, Downers Grove, IL). Values for the nonspecific retention of radioactivity on the filters accounted for less than $1 \%$ of the radioactivity in the incubation mixture and were subtracted from the total counts.

Statistics. Data comparisons were made using $t$-test, analysis of variance, and linear regression analysis using SPSSPC+ statistical package (SPSS, Chicago, IL) for personal computers.

Materials. $\left[{ }^{3} \mathrm{H}\right]$-taurine (sp act $22.4 \mathrm{Ci} / \mathrm{mmol}$ ) and $\left[{ }^{3} \mathrm{H}\right]-\beta$ - alanine (sp act $120 \mathrm{Ci} / \mathrm{mmol}$ ) were purchased from New England Nuclear (Boston, MA). Radiochemical purity was confirmed by one-dimensional thin-layer chromatography. All chemicals used to prepare the various media were reagent grade. All media were filtered through a $0.20-\mu \mathrm{m}$ filter (Gelman Instrument Co., Ann Arbor, MI) on the day of the experiment.

\section{RESULTS}

In vivo. There were no changes in the creatinine clearance or the plasma $\mathrm{Ca}$ on the different diets (Table 2). As demonstrated previously $(6,13), \mathrm{P}$ depletion resulted in hypercalciuria (urinary Ca: control $0.17 \pm 0.01$ versus $\mathrm{P}^{-} \mathrm{T}^{+} 14.75$ versus $\mathrm{P}^{-} \mathrm{T}^{-} 12.69 \pm$ $1.08 \mu \mathrm{mol} / 100 \mathrm{~g}$ body $w \mathrm{t} / \mathrm{h})$. However, there was no evidence of hydronephrosis and gross renal stone formation, as assessed during nephrectomy of the animals, because $\mathrm{P}$ depletion was induced over $1 \mathrm{wk}$ (instead of $4 \mathrm{wk}$ ).

The effect of dietary manipulation on plasma, renal tissue, and urine concentrations of taurine and $\beta$-alanine are shown in Tables 3 and 4. Plasma and renal cortical taurine concentrations were lower in animals fed the low-taurine diets than those assayed in the animals fed the control diet $(p<0.01)$. The diets did not affect the plasma and renal cortical concentration of $\beta$-alanine. On the other hand, low-taurine diets resulted in avid reabsorption of taurine from the urine, irrespective of $\mathrm{P}$ status $(p<0.01)$. $\mathrm{P}$ depletion caused a 2.6-fold increase in the urinary excretion of taurine in $\mathrm{P}^{-} \mathrm{T}^{+}$. This increase was statistically significant when compared to control $(p<0.001)$. The renal handling of $\beta$-alanine was not perturbed in any of the experimental diets.

Table 2. Effect of dietary manipulation on creatinine clearance and plasma $\mathrm{Ca}^{*}$

\begin{tabular}{ccc}
\hline Diet & $\begin{array}{c}\text { Creatinine clearance } \\
(\mathrm{mL} / \mathrm{min} / 100 \mathrm{~g} \text { body wt })\end{array}$ & $\begin{array}{c}\text { Plasma Ca } \\
(\mathrm{mg} / \mathrm{dL})\end{array}$ \\
\hline Control $\dagger(8)$ & $1.04 \pm 0.21$ & $10.27 \pm 0.17$ \\
$\mathrm{P}^{+} \mathrm{T}^{-}(7)$ & $0.98 \pm 0.18$ & $10.33 \pm 0.11$ \\
$\mathrm{P}^{-} \mathrm{T}^{-}(7)$ & $0.97 \pm 0.19$ & $10.55 \pm 0.12$ \\
$\mathrm{P}^{-} \mathrm{T}^{+}(8)$ & $1.01 \pm 0.22$ & $10.45 \pm 0.15$ \\
\hline
\end{tabular}

* Results represent the mean \pm SEM, with the number in parentheses indicating the number of samples assayed.

$\dagger$ Control, phosphate and taurine replete.

Table 3. Effect of dietary manipulation on taurine homeostasis $(p<0.001)^{*}$

\begin{tabular}{|c|c|c|c|}
\hline \multirow[b]{2}{*}{ Diet } & \multicolumn{3}{|c|}{ Taurine concentration } \\
\hline & $\begin{array}{c}\text { Plasma } \\
(\mu \mathrm{mol} / \mathrm{L})\end{array}$ & $\begin{array}{l}\text { Renal cortex } \\
(\mu \mathrm{mol} / \mathrm{g} \\
\text { wet cortex })\end{array}$ & $\begin{array}{c}\text { Urine } \\
\text { ( } \mu \mathrm{mol} / \mathrm{mg} \\
\text { creatinine })\end{array}$ \\
\hline Control $\dagger$ & $23.76 \pm 0.57(8)$ & $9.29 \pm 0.98(4)$ & $4.11 \pm 0.34(14)$ \\
\hline $\mathrm{P}^{+} \mathrm{T}^{-}$ & $14.68 \pm 1.30 \ddagger(10)$ & $3.65 \pm 0.55 \ddagger(5)$ & $0.23 \pm 0.03 \ddagger(6)$ \\
\hline $\mathrm{P}^{-} \mathrm{T}^{-}$ & $15.76 \pm 1.36 \neq(5)$ & $3.10 \pm 0.47 \ddagger(4)$ & $0.18 \pm 0.05 \ddagger(5)$ \\
\hline $\mathrm{P}^{-} \mathrm{T}^{+}$ & $25.46 \pm 1.19(4)$ & $8.37 \pm 1.43(4)$ & $10.58 \pm 1.44 \ddagger(5)$ \\
\hline
\end{tabular}

* Results represent the mean \pm SEM of four to 14 determinations, as indicated by the numbers in the parentheses.

$\dagger$ Control, phosphate and taurine replete.

$\ddagger$ Significantly different from control, $p<0.001$.

Table 4. Effect of taurine and/or P depletion on $\beta$-alanine homeostasis

\begin{tabular}{lccc}
\hline & $\begin{array}{c}\text { Renal cortex } \\
(\mu \mathrm{mol} / \mathrm{g} \\
\text { wet tissue })\end{array}$ & $\begin{array}{c}\text { Plasma } \\
(\mu \mathrm{mol} / \mathrm{dL})\end{array}$ & $\begin{array}{c}\text { Urine } \\
(\mu \mathrm{mol} / \mathrm{mg} \\
\text { creatinine })\end{array}$ \\
\hline Control* $^{+}$ & $0.49 \pm 0.06$ & $0.14 \pm 0.04$ & $0.20 \pm 0.021$ \\
$\mathrm{P}^{+} \mathrm{T}^{-}$ & $0.43 \pm 0.05$ & $0.13 \pm 0.02$ & $0.21 \pm 0.03$ \\
$\mathrm{P}^{-} \mathrm{T}^{-}$ & $0.37 \pm 0.06$ & $0.11 \pm 0.01$ & $0.19 \pm 0.01$ \\
$\mathrm{P}^{-} \mathrm{T}^{+}$ & $0.40 \pm 0.08$ & $0.12 \pm 0.04$ & $0.18 \pm 0.03$ \\
\hline
\end{tabular}

$*$ Control, phosphate and taurine replete. 
In vitro. The uptakes of taurine $(10 \mu \mathrm{M})$ (Fig. $1 A)$ and $\beta$ alanine $(10 \mu \mathrm{M})$ (Fig. $1 B$ ) over time were $\mathrm{Na}^{+}$-dependent in the presence of an inwardly directed $\mathrm{Na}^{+}$gradient $(100 \mathrm{mM})$ and were 25 times higher than that found in the absence of an external cation gradient. The peak of the "overshoot" of uptake for both of the amino acids under consideration occurred at $6 \mathrm{~min}$. The $\mathrm{Na}^{+}$-independent uptake of taurine and $\beta$-alanine, which represents less than $5 \%$ of the total uptake of the amino acid, was not affected by diet.

The uptake of taurine by BBMV prepared from animals fed the low-taurine, P-replete diet $\left(\mathrm{P}^{+} \mathrm{T}^{-}\right)$was more rapid than the uptake by BBMV prepared from the control diet. This was particularly significant during the "uphill" phase of the uptake, where the uptake was increased by 2 -fold in the taurine-deficient $\operatorname{diet}$ (control $72.14 \pm 6.34$ versus $\mathrm{P}^{+} \mathrm{T}^{-} 138.39 \pm 16.33 \mathrm{pmol} / \mathrm{mg}$ protein $/ 6 \mathrm{~min}, p<0.001)$. However, the accumulation of taurine at equilibrium was not affected.

Although $\mathrm{P}$ depletion $\left(\mathrm{P}^{-} \mathrm{T}^{+}\right)$resulted in a $2.5- \pm 0.1$-fold attenuation in the accumulation of taurine by BBMV prepared from that diet, the additive effect of taurine deprivation $\left(\mathrm{P}^{-} \mathrm{T}^{-}\right)$ enhanced taurine uptake by $1.7- \pm 0.1$-fold during the uphill portion of uptake when compared with $\mathrm{P}^{-} \mathrm{T}^{+}$. The difference in taurine uptake between $\mathrm{P}^{-} \mathrm{T}^{+}$and $\mathrm{P}^{-} \mathrm{T}^{-}$was statistically significant $(p<0.02)$. However, taurine deprivation did not normalize taurine uptake, nor did it increase uptake to levels comparable to those observed in the $\mathrm{P}^{+} \mathrm{T}^{-}$diet when $\mathrm{P}$ depletion coexisted in the same animal.

The kinetics of taurine accumulation over the range 10-250 $\mu \mathrm{M}$ by $\mathrm{BBMV}$ prepared from animals fed the above diets is
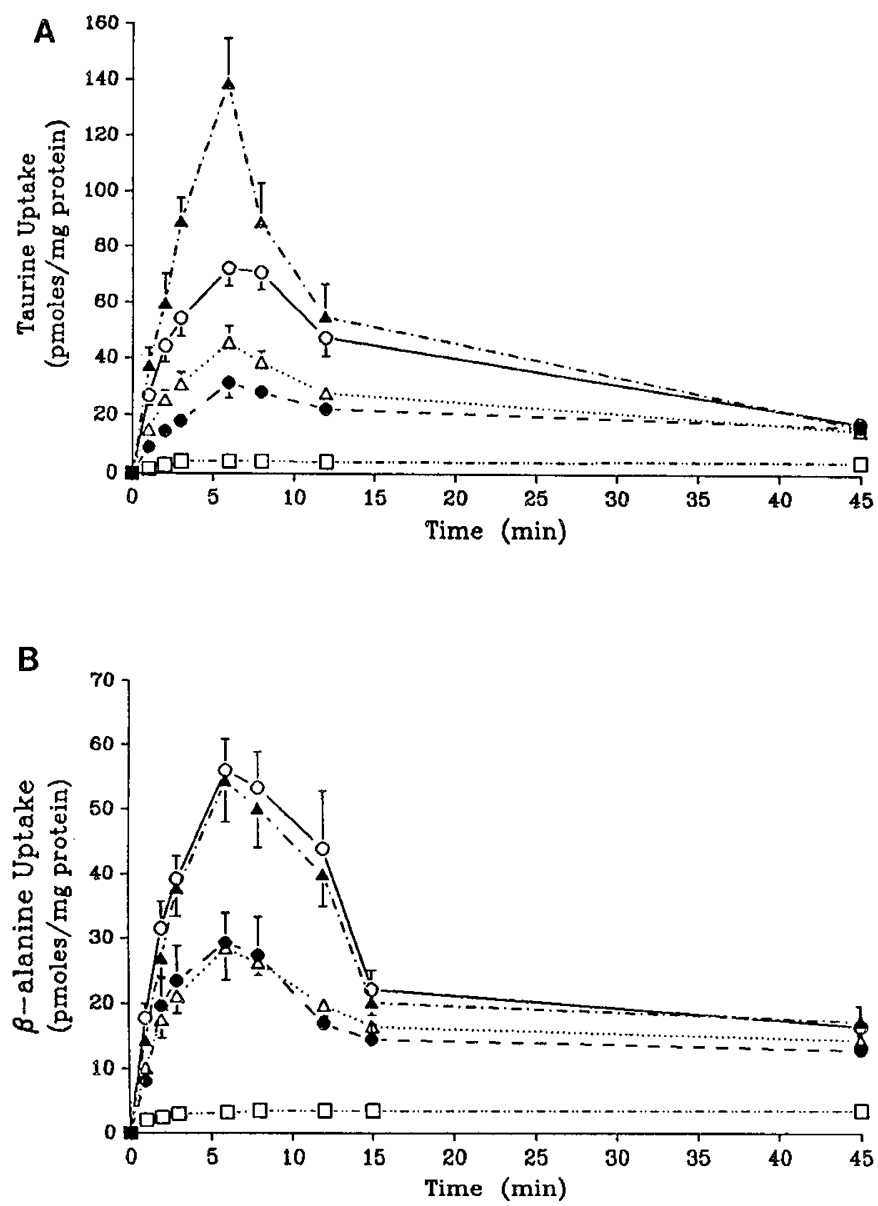

Fig. 1. The $\mathrm{Na}^{+}$-dependent uptake of taurine $(10 \mu \mathrm{M})(A)$ and $\beta$ alanine $(10 \mu \mathrm{M})(B)$ by BBMV prepared from rats fed the various diets is depicted. Each point represents the mean \pm SEM of four to 14 experiments done in duplicate. $\mathrm{O}$, control $(n=14) ; \mathrm{P}^{-} \mathrm{T}^{+}(n=8) ; \Delta$, $\mathrm{P}^{-} \mathrm{T}^{-}(n=6) ; \boldsymbol{\Delta}, \mathrm{P}^{+} \mathrm{T}^{-}(n=4) ; \square, \mathrm{Na}^{+}$-independent uptake $(n=4)$. shown in Table 5. At $30 \mathrm{~s}$, a time when uptake is on the linear portion of the uptake curve, so that the initial rate of uptake could be estimated (7), the accumulation of taurine was greatest in the taurine-deficient diets, irrespective of $P$ status. The increase was due to a change in the $\mathrm{V}_{\max }$ of uptake, and the difference from control and $\mathrm{P}^{-} \mathrm{T}^{+}$diets was statistically significant $(p<$ $0.001)$. Although there was no change in the $\mathrm{Km}$ of uptake in $\mathrm{P}^{+} \mathrm{T}^{-}, \mathrm{P}$ depletion effected a decrease in the affinity of the $\mathrm{Na}^{+}-$ taurine cotransporter. The increase in $\mathrm{Km}$ was statistically significant when compared with control $(p<0.001)$. However, the increase in the $\mathrm{Km}$ of uptake in $\mathrm{P}^{-} \mathrm{T}^{-}$was less than that observed in $\mathrm{P}^{-} \mathrm{T}^{+}(198 \pm 36.07$ versus $285.74 \pm 39.79 \mu \mathrm{M}, p<0.02)$.

There was a $48 \%$ attenuation in the uptake of $\beta$-alanine in the P-depleted diets during the uphill phase, irrespective of taurine status (Control $56.03 \pm 4.85$ versus $\mathrm{P}^{-} \mathrm{T}^{+} 29.24 \pm 4.61$ versus $\mathrm{P}^{-} \mathrm{T}^{-} 28.41 \pm 4.88 \mathrm{pmol} / \mathrm{mg}$ protein $\left./ 6 \mathrm{~min}\right)$. The difference when compared with control was statistically significant $(p<$ 0.01 ). Taurine deprivation in the presence of $P$ sufficiency did not affect the uptake of $\beta$-alanine. There was no change in the $\mathrm{V}_{\max }$ of uptake or uptake at equilibrium. However, $\mathrm{Km}$ increased 2-fold with $\mathrm{P}$ depletion $\left(\mathrm{P}^{-} \mathrm{T}^{-}\right.$and $\left.\mathrm{P}^{-} \mathrm{T}^{+}, p<0.01\right)$. $\mathrm{Km}$ remained unchanged in $\mathrm{P}^{+} \mathrm{T}^{-}$.

\section{DISCUSSION}

The transport of solutes at the renal brush border membrane increases during periods of deprivation. The data presented above demonstrate that the adaptive response manifests by an increase in the reabsorption of taurine in animals fed reduced amounts of sulfur-containing amino acids (taurine, methionine, and cysteine), as has been demonstrated by Chesney et al. (3). The adaptation is independent of the $P$ status of these animals in that there was an 18-and 23-fold decrease in the urinary excretion of taurine in the absence and presence of $\mathrm{P}$ depletion, respectively. No changes were observed in the homeostasis of $\beta$-alanine.

The augmentation in the reabsorption of taurine in states of sulfur-containing amino acid depletion is associated with a 4- to 5 -fold increase in $\mathrm{V}_{\max }$, results that confirm the findings reported by Chesney et al. $(3,24)$. When the uptake of taurine over time in $\mathrm{P}^{+} \mathrm{T}^{-}$is compared to that in $\mathrm{P}^{-} \mathrm{T}^{-}$, it becomes evident that the accumulation of taurine in the presence of $\mathrm{P}$ depletion is less than in $\mathrm{P}$ sufficiency $\left(\mathrm{P}^{+} \mathrm{T}^{-}: 138.39 \pm 16.33 \mathrm{pmol} / \mathrm{mg}\right.$ protein $/ 6$ min versus $\mathrm{P}^{-} \mathrm{T}^{-}: 45.33 \pm 3.95 \mathrm{pmol} / \mathrm{mg}$ protein $/ 6 \mathrm{~min}, p<$ $0.001)$. On the other hand, taurine deficiency induces a 1.45 -fold increase in the uptake of taurine by vesicles prepared from animals fed the $\mathrm{P}^{-} \mathrm{T}^{-}$diet compared with those fed the $\mathrm{P}^{-} \mathrm{T}^{+}$ diet. The apparent differences in the adaptive response may be related to the effect of diet on the $\mathrm{Km}$ of uptake. Although taurine deficiency alone has no effect on the affinity of the taurine symport, $\mathrm{P}$ depletion decreases the affinity of the transporter for taurine, as reflected in an increase in the $\mathrm{Km}$ of uptake, irrespective of taurine status. This may explain the persistent attenuation in the uptake of this amino acid over time with no apparent perturbation in the observed in vivo adaptive response.

There was no change in taurine uptake at equilibrium, suggesting that the alterations in symport behavior are not related to the size of the vesicle formed. In addition, although the decreased renal cortex taurine content in rats fed the low sulfur amino acid diet regulates the adaptive response (4), we don't feel that it is the sole regulatory stimulus because we would expect identical changes in taurine uptake in $\mathrm{P}^{+} \mathrm{T}^{-}$and $\mathrm{P}^{-} \mathrm{T}^{-}$. The increase in the $V_{\max }$ of uptake could be related to either the synthesis of new transporters (de novo) or the recruitment of inactive transporters. In studies that used colchicine (a substance that blocks the incorporation of preformed symporter into the membrane) in fasting rats or animals fed a high-taurine diet, there was blocking of the rise in taurine uptake in the former, and blocking of the reduction in taurine uptake in the latter (25). The data suggested that the augmentation or attenuation in the 
Table 5. Effect of diet on kinetics of taurine uptake*

\begin{tabular}{|c|c|c|c|c|}
\hline & Control† (14) & $\mathrm{P}^{-} \mathrm{T}^{+}(8)$ & $\mathrm{P}^{-} \mathrm{T}^{-}(6)$ & $\mathrm{P}^{+} \mathrm{T}^{-}(4)$ \\
\hline $\mathrm{Km}(\mu \mathrm{M})$ & $30.17 \pm 2.35$ & $285.74 \pm 39.79 \ddagger \S$ & $198.64 \pm 36.07 \ddagger \S \|$ & $36.92 \pm 6.21$ \\
\hline $\begin{array}{l}\mathrm{V}_{\max }(\mathrm{pmol} / \mathrm{mg} \text { protein/ } \\
\quad 30 \mathrm{~s})\end{array}$ & $101.01 \pm 6.49$ & $157.47 \pm 24.66$ & $503.56 \pm 165 \ddagger \pi$ & $420.6 \pm 51.32 \neq 9$ \\
\hline
\end{tabular}

* Results represent the mean \pm SEM, with the number in parentheses indicating the number of samples assayed.

$\uparrow$ Control, phosphate and taurine replete.

$¥$ Statistically different from control, $p<0.001$.

$\S$ Statistically different from $\mathrm{P}^{+} \mathrm{T}^{-}, p<0.001$.

\| Statistically different from $\mathrm{P}^{-} \mathrm{T}^{+}, p<0.02$.

I Statistically different from $\mathrm{P}^{-} \mathrm{T}^{+}, p<0.001$.

$\mathrm{Na}^{+}$-taurine symport activity is due to incorporation of already existing transporters rather than to de novo synthesis.

Our study, as well as other studies $(3-5,24)$, indicates that renal adaptive responses to dietary manipulation are membrane events. It has been shown that the change in the initial rate of $\mathrm{Na}^{+}$-taurine uptake and $\mathrm{V}_{\max }$ in the taurine-deficient animal are not related to changes in the phospholipid composition and fatty acid content of the luminal membrane (26). On the other hand, we were able to demonstrate a $40 \%$ decrease in the phosphatidylcholine and phosphatidylethanolamine content of brush border membranes prepared from animals fed the $\mathrm{P}^{-} \mathrm{T}^{+}$diet, associated with a $15 \%$ reduction in oleic, stearic, and linoleic acid, and a $15 \%$ increase in palmitic acid in the phosphatidylcholine and phosphatidylethanolamine fractions (27). Although, we have not determined the effect of $\mathrm{P}^{-} \mathrm{T}^{-}$on phospholipid composition of the membranes, we speculate that an effect similar to that found in the P-depleted animals may occur to explain the persistence in the decreased affinity of the taurine symport, despite the increase in the initial rate of uptake or the number of $\mathrm{Na}^{+}-$ taurine transporters. It is quite possible that these "new" transporters have a normal affinity for taurine, which could explain the lower $\mathrm{Km}$ for taurine uptake in $\mathrm{P}^{-} \mathrm{T}^{-}(198.64 \pm 36.07 \mu \mathrm{M})$ than in $\mathrm{P}^{-} \mathrm{T}^{+}(285.74 \pm 39.79 \mu \mathrm{M})(p<0.02)$.

The adaptive response illustrated in this study appears to be specific. When the uptake of $\beta$-alanine [an amino acid that shares the same transporter as taurine $(28,29)]$ was assayed in the same animals, we could not demonstrate a change in the $V_{\max }, \mathrm{Km}$, or uptake of $\beta$-alanine over time in taurine depletion. However, $P$ depletion (irrespective of taurine status) manifested with a decrease in the affinity of the symport for $\beta$-alanine associated with a decrease in the peak of the overshoot of uptake. These observations cannot be explained on the basis of variation in the preparation of the BBMV, inasmuch as the uptakes of taurine and $\beta$-alanine were assayed in parallel on the same day. The in vitro changes were not associated with perturbations in the urinary excretion of $\beta$-alanine. Thus, we speculate that factors other than affinity and/or number of active transporters may play a role in determining the final outcome of substrate conservation. The nature of these catalysts is yet to be determined.

In summary, we studied the effect of $\mathrm{P}$ depletion on the adaptive response to taurine deprivation in the rat. Although the rat adapts to taurine deprivation by avidly reabsorbing taurine in vivo, the decrease in the affinity of the $\mathrm{Na}^{+}$-taurine symporter persists despite the manifest increase in the $\mathrm{V}_{\max }$ of uptake.

\section{REFERENCES}

1. Friedman AL, Albright PW, Gusowski N, Padilla M, Chesney RW 1983 Renal adaptation to alteration in dietary amino acids intake. Am J Physiol 245:F159-F166

2. Rozen R, Scriver CR 1982 Renal transport of taurine adapts to perturbed taurine homeostasis. Proc Natl Acad Sci USA 79:2101-2105

3. Chesney RW, Gusowski N, Friedman AL 1983 Renal adaptation to altered dietary sulfur amino acid intake occurs at the luminal brush border membrane. Kidney Int 24:588-594

4. Chesney RW, Gusowski N, Dabbagh S 1985 Renal cortex taurine content regulates renal adaptive response to altered dietary intake of sulfur amino acids. J Clin Invest 2213-2221

5. Chesney RW, Gusowski N, Dabbagh S 1987 Studies on renal adaptation to altered dietary amino acid intake: reduced renal cortex taurine content increases the Vmax of taurine uptake by brush border membrane vesicles. Pediatr Nephrol 1:9-15

6. Dabbagh S, Epley M, Diven W, Chen T, Virji M, Ellis D 1989 Effect of vitamin $\mathrm{D}$ deficiency on amino acid excretion in the phosphate-depleted rat. Miner Electrolyte Metab 15:283-290

7. Dabbagh S, Epley M, Diven W, Ellis D 1990 Aminoaciduria of phosphate depletion manifests at the renal brush border membrane. Miner Electrolyte Metab 16:216-223

8. Rogers QR, Harper AE 1965 Amino acid diets and maximal growth in the rat. J Nutr 87:267-273

9. Huxtable RJ, Lippincott SE 1982 Relative contribution of diet and biosynthesis to the taurine content of the adult rat. Drug Nutr Interact 1:153-168

10. Levine BS, Ho K, Hodsman A, Kurokawa K, Coburn YW 1984 Early renal brush border membrane adaptation to dietary phosphorus. Miner Electrolyte Metab 10:222-227

11. Chesney RL, Friedman AL, Albright PW, Gusowski N 1982 Fasting reverses the renal adaptation to altered dietary sulfur amino acid intake. Proc Soc Exp Biol Med 170:493-501

12. Friedman A, Albright PW, Chesney RW 1981 Dietary adaptation of taurine transport by rat renal epithelium. Life Sci 29:2415-2419

13. Dabbagh S, Chesney R, Gusowski N, Mathews MC, Padilla M, Theissen M, Slatopolsky E 1989 Aminoaciduria of vitamin D deficiency is independent of PTH levels and urinary cyclic AMP. Miner Electrolyte Metab 15:221232

14. Moore S, Spackman DH, Stein WH 1958 Chromatography of amino acids on sulfated polystyrene resins. An improved system. Anal Chem 35:2055-2064

15. Hamilton PB 1963 Ion exchange chromatography of amino acids. A singlecolumn, high-resolving, fully automated procedure. Anal Chem 35:20552064

16. Booth AG, Kenny AJ 1974 A rapid method for the preparation of microvilli from rabbit kidney. Biochem $\mathbf{J} 142: 575-581$

17. Dabbagh S, Gusowski N, Chesney R, Falsetti G, Ellis M, Ellis D 1989 Cyclic AMP does not alter taurine accumulation by rat renal brush border membrane vesicles. Biochem Med Metab Biol 42:132-145

18. Haase W, Schafer A, Murer H, Kinne R 1978 Studies on the orientation of brush border membrane vesicles. Biochem J 172:57-62

19. Lowry OH, Rosebrough NJ, Farr AL, Randell RJ 1951 Protein measurement with the Folin phenol reagent. J Biol Chem 193:265-275

20. Glossman H, Neville Jr DM $1972 \tau$-glutamyltransferase in kidney brush border membranes. FEBS Lett 19:340-344

21. Dixon TF, Purdom M 1954 Serum 5'-nucleotidase. J Clin Pathol 7:341-343

22. Post RL, Sen AK 1981 Sodium and potassium-stimulated ATPase. In: Estabrook RW, Pullman ME (eds) Methods in Enzymology. Academic Press, New York, pp 762-768

23. Chesney RW, Sacktor B, Rowen RR 1973 The binding of D-glucose to the isolated rabbit renal brush border. J Biol Chem 218:2182-2191

24. Chesney RW, Gusowski N, Friedman AL, Dabbagh S, Diehl A 1985 Divergent membrane maturation in rat kidney: exposure by dietary taurine manipulation. Int J Pediatr Nephrol 6:93-100

25. Chesney RW, Jolly K, Zelikovic I, Iwahashi C, Lohstroh P 1989 Increased $\mathrm{Na}^{+}$-taurine symporter in rat renal brush border membranes: performed or newly synthesized? FASEB J 3:2081-2085

26. Chesney RW, Gusowski N, Zelikovic I 1986 Membrane fluidity and phospholipid composition in relation to sulfur amino acid intake in brush border membranes of rat kidney. Pediatr Res 20:1305-1309

27. Dabbagh S, Wong C, Epley M, Kocochis S, Falsetti G, Ellis D 1989 Effect of phosphate $(\mathrm{P})$ depletion on phospholipid (PL) composition of the renal brush border membrane (BBM). Pediatr Res 25:227A(abstr)

28. Silbernagel S 1988 The renal handling of amino acid and oligopeptides. Physiol Rev 68:911-1007

29. Jessen H, Jorgensen KE, Roigaard-Petersen H, Sheikh MI 1989 Demonstration of $\mathrm{H}^{+}$- and $\mathrm{Na}^{+}$-coupled co-transport of beta-alanine by luminal membrane vesicles of rabbit proximal tubule. J Physiol (Lond) 411:517-528 